\title{
Microbiological Case Report: Epidemiological Char- acteristics and Update of Covid-19 Cases in St. Lucia
}

\section{Sambasivarao Yaragalla ${ }^{1 *}$, Lydia Atkins ${ }^{2}$, Vaishnavee vilas wagh ${ }^{3}$, Raut Rajeshree Renukadas ${ }^{3}$, Naushad Khan ${ }^{3}$, and Navami Guru ${ }^{3}$}

${ }^{1}$ Microbiology, Spartan Health Sciences University, Community Health and Research Centre of Spartan, St. Lucia \& Country Ambassador for Microbiology to St. Lucia through ASM-American Society for Microbiology.

${ }^{2}$ Department of Clinical Science, Public Health, Spartan Health Sciences University.

${ }^{2}$ Basic Science, Spartan Health Sciences University and Members of ASM International Student Chapter St. Lucia.

\begin{abstract}
Coronavirus disease 2019 (COVID-19) is a potentially severe acute respiratory infection caused by severe acute respiratory syndrome coronavirus 2 (SARS-CoV-2.The virus was identified as the cause of an outbreak of pneumonia of unknown cause in Wuhan City, Hubei Province, China, in December 2019. The clinical presentation is that of a respiratory infection with a symptom severity ranging from a mild common cold-like illness, to a severe viral pneumonia leading to acute respiratory distress syndrome that is potentially fatal [1,2].

The clinical presentation resembles viral pneumonia, and the severity of illness ranges from mild to severe. Approximately $80 \%$ of patients present with mild illness, $14 \%$ present with severe illness, and $5 \%$ present with critical illness. Severe illness is associated with older age and the presence of underlying health conditions. Older patients and/or those with comorbidities may present with mild symptoms, but have a high risk of deterioration. Atypical presentations may occur, especially in older patients or patients who are immunocompromised. To aid the analysis and tracking of the COVID-19 we collected and curated individual-level data from national, provincial, and municipal health reports, as well as additional information from online reports. In this study we presented only the Microbiological History and an Update of COVID-19 Cases in St. Lucia [3-5].
\end{abstract}

Corresponding author: Sambasivarao Yaragalla, Microbiology and Immunology, Spartan Health Sciences University, Community Health and Research Centre of Spartan, St. Lucia, Caribbean. E-Mail: siva@spartanmed.org

Received: April 27, 2020; Accepted: May 06, 2020; Published: May 10; 2020

Keywords: Covid-19 Cases, Microbiological, SARS-CoV-2, Pneumonia 
Citation: Sambasivarao Y, Lydia A, Vaishnavee V, Raut Rajeshree R, Naushad k, Navami G (2019) Microbiological Case Report: Epidemiological Characteristics and Update of Covid-19 Cases in St. Lucia. Journal of Infectious Diseases \& Case Reports. SRC/JIDSCR/107. DOI: https://doi.org/10.47363/JIDSCR/2020(1)104.

\section{Introduction}

Coronavirus Disease 2019 (COVID-19) is a novel coronavirus first discovered in Wuhan City, Hubei Province, China in November 2019. On January 22, 2020, the Chinese Government declared a state of emergency due to the unprecedented outbreak of atypical pneumonia in China, from COVID-19. The World Health Organization declared the outbreak a "public health emergency of international concern" on January 30, 2020 and characterized it as a pandemic on March 11, 2020 [6-9].

As of April 25, 2020, the WHO reported over two and a half million $(2,774,135)$ cases of COVID-19, and 190,871 related deaths across two hundred and thirteen (213) affected countries, territories or areas. Public health measures in response to the pandemic are coming at a high cost as the national policies of many countries focus on the prevention of the global spread of COVID-19. The global community has taken various approaches to containment of the virus, with many countries implementing what has been describes as draconian measures of social distancing, which required country-wide lockdowns and 24-hour curfews restricting the movement of persons [10].

This continually evolving pandemic that is without precedent in the last century threatens to disproportionately affect developing countries like the Caribbean, with the potential to overwhelm under-resourced health facilities and fragile health systems which have limited absorptive capacity for an outbreak at less the scale of what has been seen in more developed countries like China, Europe and the United States. This paper describes the outbreak of COVID-19 in Saint Lucia and reviews the epidemiologic characteristics based on data of 15 confirmed cases between March 14, 2020 and April 10, 2020.

\section{Methods}

This report was compiled using data from official government sources, and from additional data confirmed and announced by the press. This method was adopted from peer-reviewed scientific papers that reported primary data as the gold standard for data inclusion.

Government sources included press releases on the official websites of Ministry of Health and Wellness or Regional Public Health Organizations, as well as updates provided by the official social media accounts of governmental or public health institutions [5].

\section{Ethics Statement}

National ethical approval or individual consent was not applicable for this report. Publicly published data was used in this study, and therefore consents from individual patients have not been obtained.

\section{Results \\ Case Presentations}

Case-1(March 14, 2020): A British female,63 years old with travel history from United Kingdom entered St Lucia from Grenada with her husband via British Airways [11].

Case-2 (March 14, 2020): A fifty-three-year-old male with an active travel history with France being his last port of departure [12].

Case-3 (March 23, 2020): A 43 year old female with a travel history to the US with experiencing flu-like symptoms [13]. Case-4 (March 28, 2020): A 49-year-old female national, nurse by profession, with a travel history to the United Kingdom [14].

Case-5 (March 30, 2020): A 24 year old female with travel history to New York [15].

Case-6 (March 30, 2020): A 45 year old female with a travel history to New York [15].

Case-7 (March 30, 2020): A 47 female with recent travel history to Barbados and Dominica [15].

Case-8 (March 30, 2020): A 36 male who had travel history to Barbados [15].

Case-9 (March 30, 2020): A 74 year old female with no travel history or known contact with an individual with travel history [15].

Case-10 (March 31, 2020): A 37 year old female with no travel history but was in contact with someone within the tourism industry [16].

Case-11 (March 31, 2020): A 34 year old female with no travel history and no known contact with someone with significant travel history [16].

Case-12 (March 31, 2020): A 54 year old female with no travel history [16].

Case-13 (March 31, 2020): A 40 year old male with no travel history but contact with persons with recent travel into Saint Lucia [16].

Case-14 (April 4, 2020): A 56-year-old female who is the contact of one of our previous confirmed cases [17].

Case-15 (April 10, 2020): An 18-year-old male who is a close contact of a previously confirmed case [18]. 


\section{Epidemiologic Characteristics}

Examination of demographic characteristics of the 15 confirmed patients in Saint Lucia showed that 11 (73.3\%) and $4(26.6 \%)$ were female and male, respectively. Thirteen of the patients were nationals, with two identified as nonnational visitors from Europe [19].

The median age of all patients was 44 years $( \pm 15)$ with a range of (18-74), (Table 1). In total, 8 patients constituted index cases, while 7 were first-generation contact cases (Graph 2). The epidemic curve plotted according to the date of diagnosis, ranges from March 14, 2020 to April 15, 2020 and shows that the highest number of cases were on March 30, 2020 (Graph $3)$.

\begin{tabular}{|l|l|}
\hline Characteristics & $\mathrm{N}(\%)$ \\
\hline Female & $11(77.3)$ \\
\hline Age (yrs) & \\
\hline$<20$ & $1(6.7)$ \\
\hline $20-29$ & $1(6.7)$ \\
\hline $30-39$ & $3(20)$ \\
\hline $40-49$ & $5(33.3)$ \\
\hline $50-59$ & $3(20)$ \\
\hline $60-69$ & $1(6.7)$ \\
\hline $70-79$ & $1(6.7)$ \\
\hline Source of Infection & \\
\hline Index case (n=8) & \\
\hline Europe & $3(37.5)$ \\
\hline USA & $3(37.5)$ \\
\hline Caribbean & $2(25)$ \\
\hline $\begin{array}{l}\text { Contact case/ 1st genera- } \\
\text { tion }\end{array}$ & $7(46.7)$ \\
\hline
\end{tabular}

Table 1: Summary of epidemiologic characteristics of 2019 novel coronavirus disease of the 15 cases in Saint Lucia.

\begin{tabular}{|l|l|l|l|l|l|}
\hline Country & $\begin{array}{l}\text { Total } \\
\text { Cases }\end{array}$ & $\begin{array}{l}\text { Total } \\
\text { Recov- } \\
\text { ered }\end{array}$ & $\begin{array}{l}\text { Active } \\
\text { Cases }\end{array}$ & $\begin{array}{l}\text { Total } \\
\text { Deaths }\end{array}$ & $\begin{array}{l}\text { Total } \\
\text { Tests }\end{array}$ \\
\hline $\begin{array}{l}\text { Saint } \\
\text { Lucia }\end{array}$ & 15 & 15 & 4 & 0 & 344 \\
\hline
\end{tabular}

Table 1: Corona virus cases in St.Lucia [20].

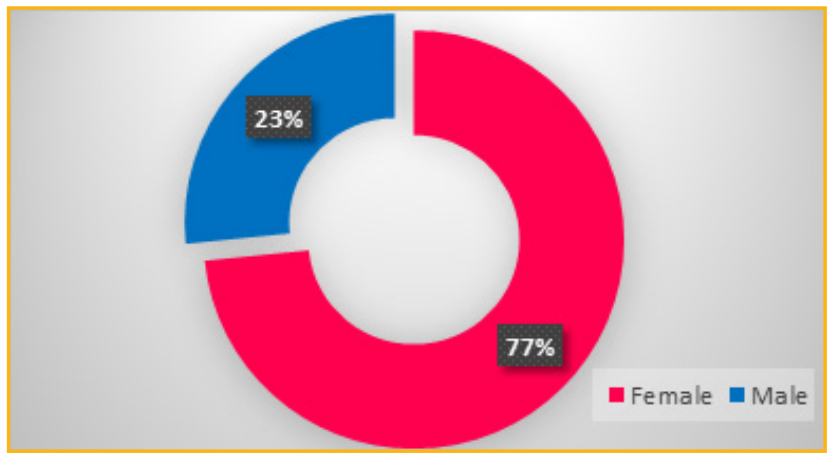

Figure 1: showing Sex Distribution of COVID19 Reported Cases in St. Lucia.

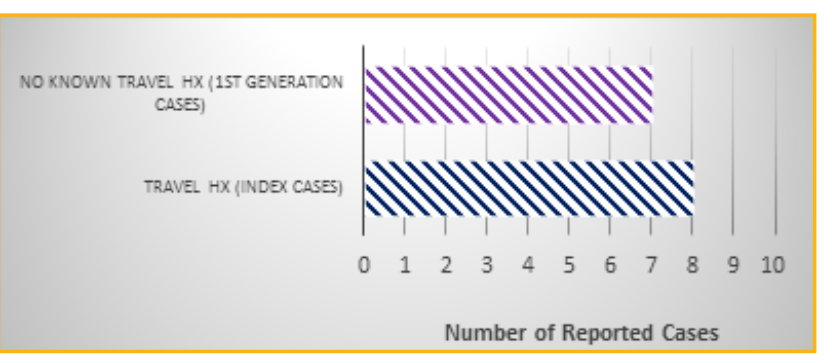

Figure 2: Travel History Status for Reported COVID19 Cases.

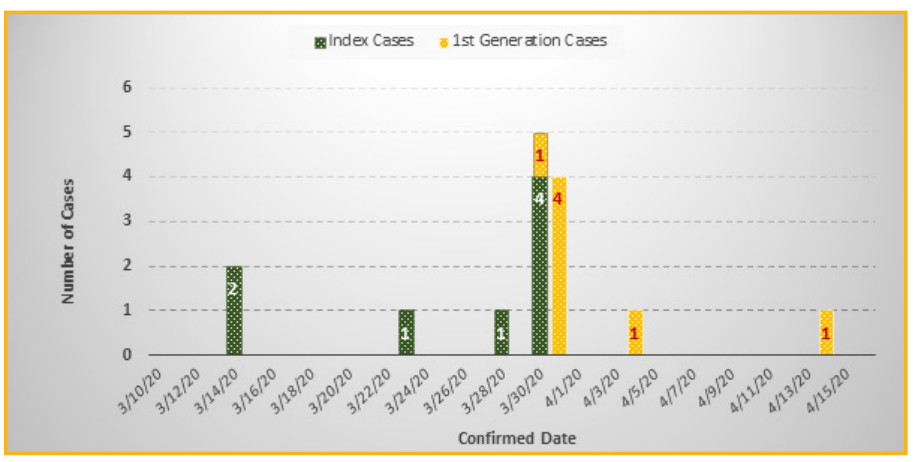

Figure 3: Epidemic curve according to diseaseconfirmed date for the 15 confirmed cases in Saint Lucia

\section{Discussion}

As of April 22, 2020, Saint Lucia reported a total of 15 confirmed cases of COVID-19. Of these 8 had travelled history to Europe, USA and the Caribbean, and were infected outside of Saint Lucia. The remaining 7 were identified as 1st generation cases, 2 having contact with known locally confirmed cased and 5 with known 
Citation: Sambasivarao Y, Lydia A, Vaishnavee V, Raut Rajeshree R, Naushad k, Navami G (2019) Microbiological Case Report: Epidemiological Characteristics and Update of Covid-19 Cases in St. Lucia. Journal of Infectious Diseases \& Case Reports. SRC/JIDSCR/107. DOI: https://doi.org/10.47363/JIDSCR/2020(1)104.

contact with persons with significant travel history.

To date, all of the positive cases of COVID-19 in St. Lucia have recovered. This now places Saint Lucia at a 100 percent recovery of all COVID-19 cases. Among the 15 cases St. Lucia recorded were individuals who fell within the category of high risk by virtue of some being elderly as well as living with chronic illness. They too recovered well with no complications or needed critical care [21].

Saint Lucia's strategic approach to COVID-19 has focused on containment and aggressive preventive measures to flatten the curve and slow the spread of the virus. Like many other Caribbean countries, Saint Lucia implemented early social distancing policies that have proven effective in countries such as China [2].

\section{Conclusion}

Saint Lucia's early successes at flattening the curve, while based on limited data, maybe due to the rigorously applied nonpharmaceutical, public health measures to interrupt chains of human-to-human transmission. The high transmissibility, substantial fatal outcomes in high-risk groups (elderly and persons with compromised immune system response due to chronic conditions, and its ability to cause huge societal and economic disruption and the draconian measures needed to be implemented in response, makes COVID-19 unique among human coronaviruses. The novel nature, our continuously evolving understanding of COVID-19, and the possibility for asymptomatic cases in the population requires that the non-pharmaceutical interventions applied in Saint Lucia needs to be supported with aggressive parallel testing for surveillance of asymptomatic cases.

\section{Acknowledgement}

We are sincerely thankful for Dr. Gurumurthy and Dr. Sreekrishna Penna from Spartan health Sciences University for Institutional Review Board approval and completion of this case in the department of Clinical Sciences, Microbiology \& Immunology. I would like to express my special thanks of gratitude to St Luciass Chief Medical Officer, Dr Sharon Belmar-George \& Ministry of Health for the data inclusion from Government sources include press releases on the official websites of Ministries. We also thankful to Dr. Rajeev Pandey for CHARCOS and Institutional Review Board approval at the Spartan Health Sciences University.

\section{References}

1. Coronaviridae Study Group of the International Committee on Taxonomy of Viruse (2020) The species severe acute respiratory syndrome-related coronavirus: classifying 2019-nCoV and naming it SARS-CoV-2. Nat Microbiol Apr 5: 536-44.

2. Ren LL, Wang YM, Wu ZQ, Xiang ZC, Guo L et al. (2020) Identification of a novel coronavirus causing severe pneumonia in human: a descriptive study. Chin Med J (Engl) 133: 1015-1024.

3. Zhonghua Liu Xing Bing Xue Za Zhi (2020) The epidemiological characteristics of an outbreak of 2019 novel coronavirus diseases (COVID-19) in China [in Chinese], Novel Coronavirus Pneumonia Emergency Response Epidemiology Team 41: 145-51.

4. Centers for Disease Control and Prevention (2020) Coronavirus disease 2019 (COVID-19): people who are at higher risk for severe illness. [Internet publication].

5. Bo $\mathrm{Xu}$, Bernardo Gutierrez, Sumiko Mekaru, Kara Sewalk, Lauren Goodwin, etal. (2020) Epidemiological data from the COVID-19 outbreak, real-time case information, Scientific Data vol 7: 106.

6. Gupta D (2020) Effect of Ambient Temperature on COVID-19 Infection Rate https://papers.ssrn.com/sol3/ papers.cfm?abstract_id $=3558470$.

7. Xie J, Jhu Y (2020) Association between ambient temperature and COVID-19 infection in 122 cities from China, Science of the Total Environment 724: 138201.

8. Rong K, Zhou D, Tang K, Cong Cao (2020) When COVID-19 Met Short Videos: A We-governance Practice in China, Social Science and Research Network.

9. Guan W, Ni Z, Hu Y, Liang W, Ou C, et al. (2020) Clinical characteristics of coronavirus disease 2019 in China, New England Journal of Medicine.https://www.nejm.org/doi/ pdf $/ 10.1056 /$ NEJMoa2002032?articleTools=true.

10. WHO (2020) Coronavirus Situation Report. World Health Organization. [Online] [Cited:] https:// www.who.int/docs/default-source/coronaviruse/ situation-reports/20200314-sitrep-54-covid-19. pdf?sfvrsn=dcd46351_6.

11. http://www.govt.lc/news/saint-lucia-confirms-its-firstcase-of-covid-19.

12. http://www.govt.lc/news/saint-lucia-confirms-secondcase-of-covid-19.

13. https://stluciatimes.com/saint-lucia-confirms-3rdcovid-19-case/.

14. http://www.govt.lc/news/saint-lucia-records-fourth- 
confirmed-case-of-covid-19.

15. http://www.govt.lc/news/saint-lucia-records-five-newcases-of-covid-19.

16. 16. http://www.govt.lc/news/saint-lucia-records-fournew-cases-of-covid-19.

17. http://www.govt.lc/news/saint-lucia-records-casenumber-14.

18. 18. http://www.govt.lc/news/saint-lucia-records-casenumber-15.
19. http://www.govt.lc/news/report-on-saint-luciaresponse-to-covid-19.

20. https://www.worldometers.info/coronavirus/?utm campaign $=$ homeAdvegas $1 ? \% 20$.

21. http://www.govt.lc/news/100-percent-recovery-ofcovid-19-cases.

Copyright: (2020. Sambasivarao Yaragalla. This is an open-access article distributed under the terms of the Creative Commons Attribution License, which permits unrestricted use, distribution, and reproduction in any medium, provided the original author and source are credited. 